\title{
Are Long-Term Changes in Mixed Layer Depth Influencing North Pacific Marine Heatwaves?
}

\section{Dillon J. Amaya, Michael A. Alexander, Antonietta Capotondi, Clara Deser, Kristopher B. Karnauskas, Arthur J. Miller, and Nathan J. Mantua}

\begin{abstract}
AFFILIATIONS: Amaya-Cooperative Institute for Research in Environmental Sciences (CIRES), University of Colorado Boulder, Boulder, Colorado; Alexander-NOAA Physical Sciences Laboratory, Boulder, Colorado; Capotondi-CIRES, University of Colorado Boulder, and NOAA Physical Sciences Laboratory, Boulder, Colorado; Deser-National Center for Atmospheric Research, Boulder, Colorado; Karnauskas-CIRES and Department of Atmospheric and Oceanic Sciences, University of Colorado Boulder, Boulder, Colorado; Miller-Scripps Institution of Oceanography, University of California San Diego; Mantua-NOAA Southwest Fisheries Science Center, Fisheries Ecology Division
\end{abstract}

CORRESPONDING AUTHOR: Dillon J. Amaya, dillon.amaya@colorado.edu

DOI:10.1175/BAMS-D-20-0144.1

A supplement to this article is available online (10.1175/BAMS-D-20-0144.2)

\section{CO2021 American Meteorological Society}

For information regarding reuse of this content and general copyright information, consult the AMS Copyright Policy.
The 2019 Northwest Pacific marine heatwave was amplified by natural, multidecadal shoaling of the ocean mixed layer; anthropogenic mixed layer shoaling will amplify marine heatwaves in the future.

n boreal summer 2019, the northeast Pacific Ocean (NEPac) experienced a resurgence of extremely warm upper ocean temperatures (Fig. 1a). The strength and pattern of the sea surface temperature anomalies (SSTAs) earned this event the moniker "Blob 2.0" (Amaya et al. 2020; hereafter A2020), a reference to the original warm "Blob" that initiated a multi-year marine heatwave (MHW) that devastated regional ecosystems over 2014-16 (Bond et al. 2015; Cavole et al. 2016; Amaya et al. 2016; Piatt et al. 2020). In particular, the intraseasonal persistence of the 2019 Blob 2.0 generated similar widespread concern among fishery and wildlife managers for sensitive marine ecosystems along the west coast of North America (NOAA 2019).

Blob 2.0 primarily resulted from a record minimum mixed layer depth (MLD; Fig. 1a shading), which formed due to weaker than normal wind speeds and strong surface heating from reduced cloud cover (A2020). Equation (1) illustrates how shallow mixed layer depths affect mixed layer temperature changes, $\partial T_{m}^{\prime} / \partial t$, when consider- 
(a)

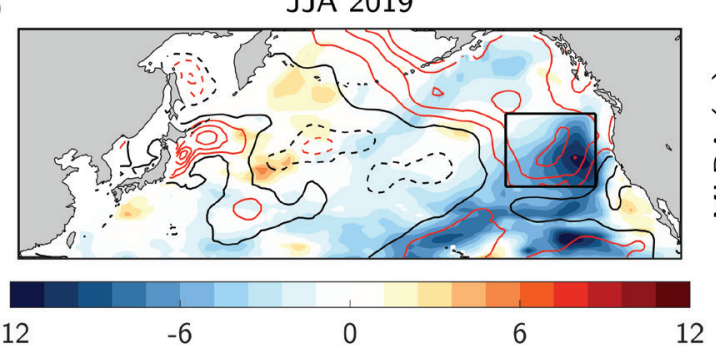

(b)

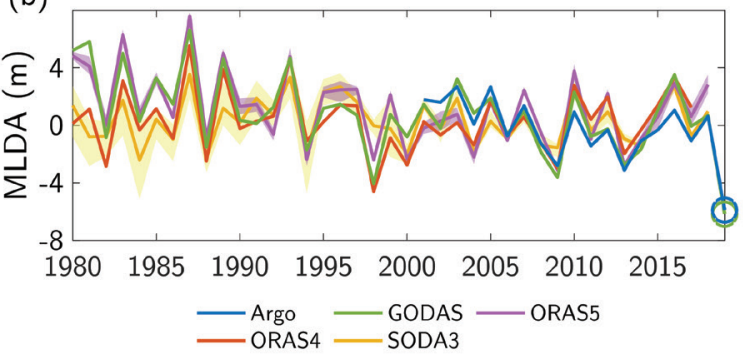

(d)

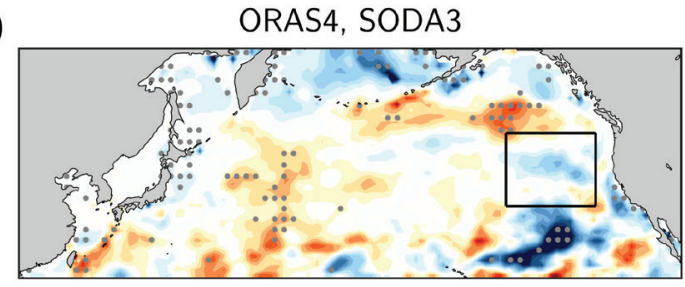

(c)

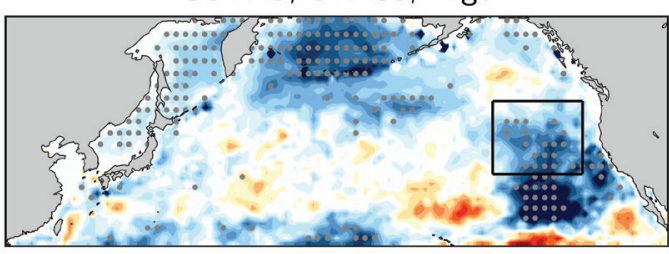

1.2

2.4

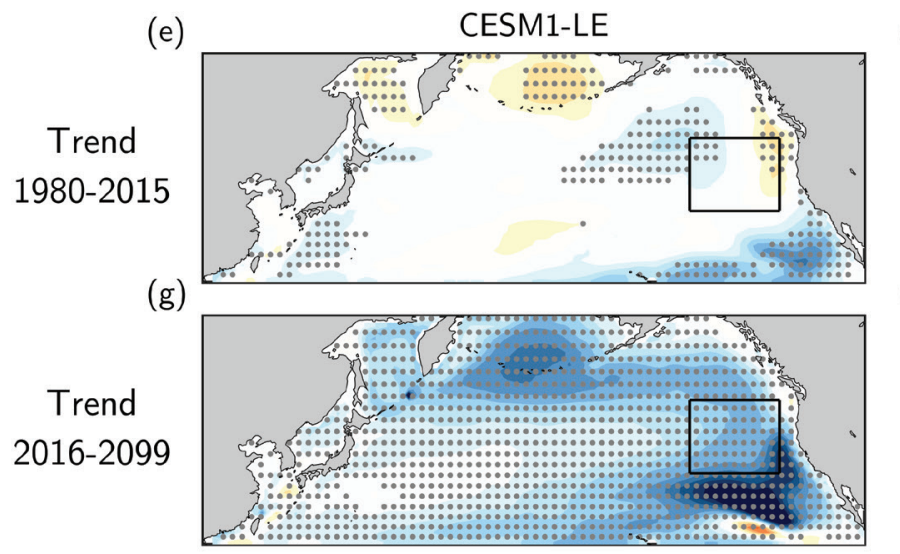

(f)

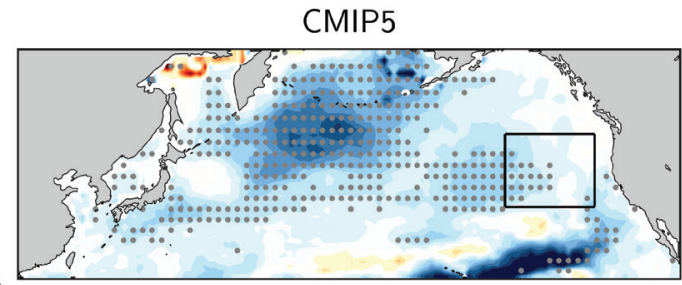

(h)

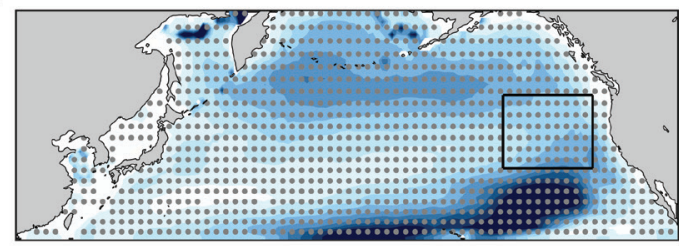

$\mathrm{m} \mathrm{dec}{ }^{-1}$

$-1.2$

$-0.6$

0

0.6

1.2

Fig. 1. (a) JJA 2019 MLDAs ( $\mathrm{m}$; shading) and SSTAs ( ${ }^{\circ} \mathrm{C}$; contours, positive solid and negative dashed) from Argo and GODAS, respectively. Contour interval is $0.5^{\circ} \mathrm{C}$ starting at $0.5^{\circ} \mathrm{C}$ (solid black). (b) MLDAs for five observational analyses (Table 1) averaged in the black box (i.e., $34^{\circ}-47^{\circ} \mathrm{N}, 213^{\circ}-232^{\circ} \mathrm{W}$ ) shown in each map. Circles mark 2019 values. Shading for SODA3 and ORAS5 represents the full range (min-to-max) across respective ensembles. (c),(d) Observed JJA MLD trends ( $m$ decade ${ }^{-1}$; shading) from 1980 to 2015 averaged across two groupings: (c) GODAS, ORAS5, and Argo and (d) ORAS4 and SODA3. (e),(f) Simulated JJA MLD trend ( $m$ decade $^{-1}$; shading) from 1980 to 2015 in ensemble means of CESM1-LE and CMIP5. (g),(h) As in (e),(f), but for the period 2016-99. All trends based on linear least squares fit. Stippling represents $95 \%$ significance for a Mann-Kendall test.

ing only local heat sources and sinks (i.e., neglecting advection) and separating each budget term into mean and perturbation components:

$$
\begin{gathered}
\rho c_{p} \frac{\partial T_{m}^{\prime}}{\partial t} \approx \frac{Q^{\prime}}{\bar{h}}-\frac{\bar{Q} h^{\prime}}{\bar{h}^{2}}-\left(\frac{Q^{\prime} h^{\prime}-\overline{Q^{\prime} h^{\prime}}}{\bar{h}^{2}}\right), \\
\text { I } \quad \text { II }
\end{gathered}
$$

where $Q$ is the net surface heat flux into the ocean, $h$ is the MLD, $\rho$ is seawater density, and $c_{p}$ is the specific heat of seawater. Primes denote time anomalies and overbars 
represent time mean values. For the full derivation see Alexander and Penland (1996). For Blob 2.0, strong downward $Q$ anomalies (i.e., positive $Q^{\prime}$ ) led to excess heat being distributed over a thin climatological mixed layer, since $\bar{h}$ is small in summer (term I). More importantly, anomalous MLD shoaling (i.e., negative $h^{\prime}$ ) contributed to upper ocean warming through term II (A2020).

As discussed in A2020, the 2019 MLD anomalies (MLDAs) superpose on a MLD shoaling trend from 1980 to the present, which they suggest may indicate a role for anthropogenic forcing. Upper ocean warming in response to future climate change is expected to reduce mixing and shoal the mixed layer (Capotondi et al. 2012; Alexander et al. 2018). A long-term trend in the mean MLD would have significant implications for SSTAs since, according to Eq. (1), decreasing the mean MLD $(\bar{h})$ results in a stronger temperature response for the same heat flux and MLD anomalies. Therefore, if the observed MLD shoaling first reported by A2020 is robust across different datasets and consistent with the projected response to anthropogenic climate change, then Blob 2.0 may have been exacerbated by anthropogenic forcing. Here, we investigate the presence of NEPac MLD trends in a suite of observational analyses. We then compare these results to coupled model simulations to assess the potential influence of anthropogenic climate change on NEPac MLD trends, and by extension, on the likelihood and intensity of the 2019 MHW.

\section{Data and methods.}

For observed MLD, we use monthly mean data from the NOAA Global Ocean Data Assimilation System (GODAS; Behringer and Xue 2004), ECMWF Ocean Reanalysis System 4 (ORAS4; Balmaseda et al. 2013) and 5 (ORAS5; Zuo et al. 2019), Simple Ocean Data Assimilation version 3 (SODA3; Carton et al. 2018), and gridded Argo profiles (Hosoda et al. 2008). See Table 1 for more details.

We estimate the externally forced MLD trends using the Community Earth System Model version 1 Large Ensemble (CESM1-LE; Kay et al. 2015). Additionally, we use 13 models from phase 5 of the Coupled Model Intercomparison Project (CMIP5; Taylor et al. 2012) with the same radiative forcing protocol. Model details are provided in Table 1 and also Table ES1 in the supplemental material. We use the ensemble mean of each model ensemble (CESM1-LE and CMIP5) as two estimates of the forced response.

To compare trends across datasets, we calculate MLD in each observational analysis and coupled model simulation as the interpolated depth at which potential density first exceeds $0.125 \mathrm{~kg} \mathrm{~m}^{-3}$ greater than the surface value (Suga et al. 2004). For datasets that do not include potential density, we calculate it from monthly mean potential temperature and salinity profiles. To compare to Blob 2.0, we only analyze MLD values averaged over boreal summer [June-August (JJA)]. Unless otherwise specified, all anomalies are relative to the period 2001-15, which is the longest overlapping period for the data used in this study.

Our results are not sensitive to the choice of MLD definition. Additionally, while it is preferred to calculate long-term MLD trends based on daily mean values, many of the datasets only provided monthly means (e.g., ORAS4, ORAS5, CESM1-LE, and CMIP5). However, we do not expect our results or conclusions to be influenced by this choice, since the temperature and density gradients are very strong at the base of the mixed layer in summer. Finally, we define the term "NEPac" to represent the region bounded by $34^{\circ}-47^{\circ} \mathrm{N}, 213^{\circ}-232^{\circ} \mathrm{W}$ (black box, Fig. 1), the same area used in A2020.

\section{Results.}

MLD trends in observations. We begin by assessing MLD trends in observations. Interannual MLD variability in the NEPac is quite consistent across the various observational analyses (Fig. 1b, Table 1), particularly during the Argo era (2001-present). However, earlier in the instrumental record, two groupings emerge, with GODAS and ORAS5 exhibiting a more pronounced shoaling trend than ORAS4 and SODA3. While the 
Table 1. Observational and coupled model data used in this study and their JJA-averaged MLD trends in the NEPac (black box; Fig. 1a). For ensemble datasets, the mean MLD trend is reported with minimum and maximum ensemble trends in parentheses. For Argo data, the trend is reported for 2001-19. Significant trends are bolded and are based on a $\mathbf{9 5 \%}$ Mann-Kendall test. Datasets marked with an asterisk (*) did not provide potential density as a variable. Therefore, the potential density used to calculate MLD for these datasets is based on their respective temperature and salinity fields.

\begin{tabular}{|c|c|c|c|}
\hline Datasets & Data availability & Ensemble details & $\begin{array}{l}\text { NEPac MLD trends } \\
\quad\left(m \text { decade }^{-1}\right)\end{array}$ \\
\hline Observations & & & Trend for $1980-2015$ \\
\hline GODAS* & $1980-2019$ & & -1.3 \\
\hline ORAS5* & $1979-2018$ & $\begin{array}{l}5 \text { members, different initial } \\
\text { conditions }\end{array}$ & $-1.2(-1.2$ to -1.2$)$ \\
\hline Argo & 2001-19 & & -2.2 \\
\hline ORAS4* & $1958-2017$ & & -0.3 \\
\hline SODA3.X & $\begin{array}{l}\text { SODA3.3.2: } 1980-2018 \\
\text { SODA3.4.2: 1980-2018 } \\
\text { SODA3.11.2: } 1980-2015 \\
\text { SODA3.12.2: } 1980-2017\end{array}$ & $\begin{array}{l}4 \text { members, different atmo- } \\
\text { spheric reanalysis forcing }\end{array}$ & $-0.2(-0.6$ to 0.6$)$ \\
\hline Obs. avg. (excluding Argo) & & & -0.7 \\
\hline Models & & & $\begin{array}{l}\text { Trend for 1980-2015/project- } \\
\text { ed trend for 2016-2099 }\end{array}$ \\
\hline CESM1-LE & $1920-2100$ & $\begin{array}{l}40 \text { members, historical forc- } \\
\text { ing until } 2005, \text { RCP } 8.5 \text { after }\end{array}$ & $\begin{array}{l}-0.0(-0.6 \text { to } 0.7) /-0.6 \\
(-0.7 \text { to }-0.3)\end{array}$ \\
\hline CMIP5* & $1900-2099$ & $\begin{array}{l}13 \text { models, one member each } \\
\text { (see Table ES1 for model } \\
\text { details), historical forcing } \\
\text { until 2005, RCP8.5 after }\end{array}$ & $\begin{array}{l}-0.2(-0.6 \text { to } 0.5) /-0.4 \\
(-1.0 \text { to }-0.1)\end{array}$ \\
\hline Forced model avg. & & & $-0.1 /-0.5$ \\
\hline
\end{tabular}

magnitude of the observed MLD shoaling varies among datasets, the average NEPac trend $\left(-0.7 \mathrm{~m} \mathrm{decade}^{-1}\right)$ is significant at the $95 \%$ confidence level (Table 1). Given that the climatological JJA MLD in the NEPac region is $\sim 18 \mathrm{~m}$, such a trend would correspond 15\% decrease in the mean MLD from 1980 to 2015.

Creating two groupings of observational analyses (GODAS, ORAS5, and Argo vs ORAS4 and SODA3), we produce two observational MLD trend maps from 1980 to 2015. The average of GODAS, ORAS5, and Argo shows widespread MLD shoaling trends with two main centers of action, one around the Aleutian Islands and one off the California coast (Figs. 1c,d; see also Fig. ES1). While the average of ORAS4 and SODA3 shows weaker MLD trends overall, the two centers of action are also generally present in these data (Fig. ES1). Additionally, the close spatial correspondence of the 2019 MLDAs near California (Fig. 1a, shading) with some of the observed trends (Fig. 1c and Fig. ES1) suggests that this extreme event was likely exacerbated by these longer-term features.

MLD trends in climate models. Are these and other North Pacific MLD trends attributable to anthropogenic forcing? To address this question, we show maps of JJA MLD trends from 1980 to 2015 for the ensemble means of CESM1-LE and CMIP5 to estimate the forced component (Figs. 1e,f). There is some spatial correspondence with the observational analyses (Fig. 1c and Fig. ES1), especially with CMIP5. The spatial similarities between the historical trends in observations and the forced trends in models are even more apparent when the latter are extended into the future (2016-99; Figs. 1g,h). For the NEPac, the JJA MLD time series show significant forced trends in both the CESM1-LE 
$\left(-0.6 \mathrm{~m}\right.$ decade $\left.^{-1}\right)$ and CMIP5 (-0.4 $\left.\mathrm{m} \mathrm{decade}^{-1}\right)$ during 2016-99, which amounts to $\sim 4$ $m$ MLD shoaling by the end of the twenty-first century (Fig. 2a). However, many of the observed NEPac trend estimates are larger than the CESM1-LE and CMIP5 ensemble mean trends from 1980 to 2015 (Table 1), suggesting that the observations contain significant contributions from internal variability.

Climate change impacts on future MLD extremes. How extreme were the 2019 MLDAs relative to the full range of internal variations in present and future climates? Diagnosing the 2019 event in this context will help us understand how future MLDAs contribute to future MHWs.

Given that the magnitude of interannual variability of NEPac JJA MLD in CESM1-LE compares well with observations (standard deviation of $2.1 \mathrm{vs} 2.3 \mathrm{~m}$, respectively, based on detrended data during 1950-2018), this model ensemble can be used to contextualize the observations. Compared to the CESM1-LE probability distribution function (PDF) for a 30-yr period centered on 2019, the observed 2019 NEPac MLDA was an extremely rare event, falling at the far negative tail of the model distribution (Fig. 2b). When viewed against the projected decrease in the model's MLD by 2100, the observed 2019 anomalies become less extreme, rising from percentile ranks of $0.06 \%$ and $0.08 \%$ to $7.6 \%$ and $10.4 \%$ for GODAS and Argo, respectively.

Climate change impacts of MLD on future SST extremes. Long-term shoaling of the mean MLD also has important implications for the magnitude of future SST extremes. We illustrate this by calculating Eq. (1) terms I and II in CESM1-LE for the NEPac box. In this region, the CESM1-LE JJA mean net surface heat flux $(\bar{Q})$ increases by $\sim 10 \mathrm{~W} \mathrm{~m}^{-2}$ by the end of the century, while the mean $\operatorname{MLD}(\bar{h})$ decreases by $\sim 4 \mathrm{~m}$ (Fig. 3a). As a result, the denominators of terms I and II decrease, while the numerator of term II increases, suggesting that both term I and II will contribute to more mixed layer warming for the same heat flux anomaly $\left(Q^{\prime}\right)$ and MLDA $\left(h^{\prime}\right)$ in the future.

By fixing $Q^{\prime}$ and $h^{\prime}$ at observed JJA 2019 values $\left(Q^{\prime}=7.8 \mathrm{~W} \mathrm{~m}^{-2}\right.$ and $h^{\prime}=-6.2 \mathrm{~m}$ in NEPac using ERA5 and GODAS, respectively) and calculating terms I and II in a 30 -yr sliding window, we see that the superposition of increasing $\bar{Q}$ and decreasing $\bar{h}$ leads to term II dominating over term I (Fig. 3b). In particular, for the same $Q^{\prime}$ and $h^{\prime}$, term II is projected to generate SSTAs that are $\sim 4.5^{\circ} \mathrm{C}$ warmer in $2071-2100$ than in 2001-30. Term III, which represents the nonlinear interaction of $Q^{\prime}$ and $h^{\prime}$, is negligible. Therefore, in the absence of compensating damping from processes such as

(a)

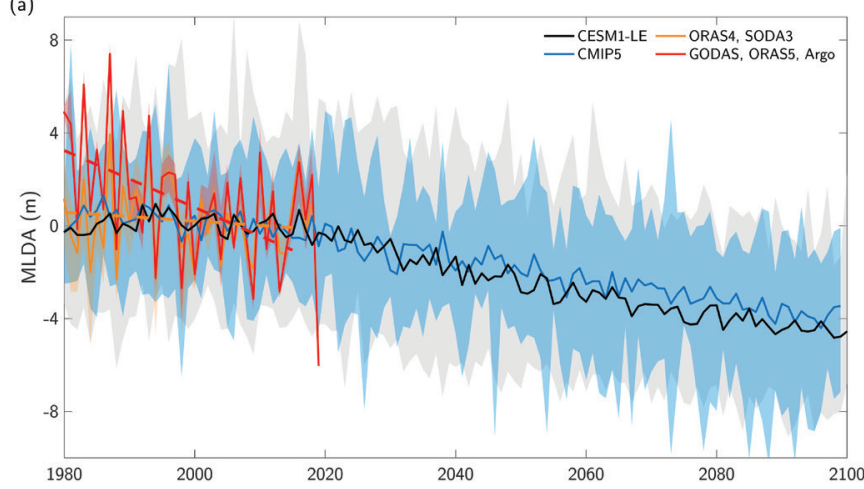

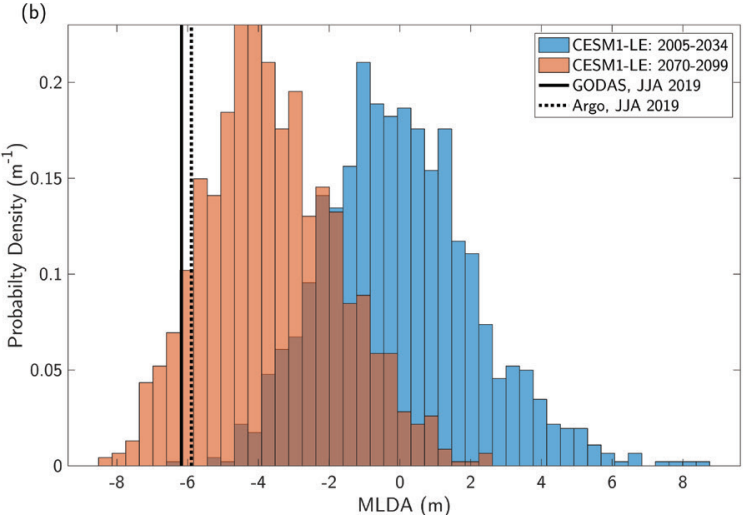

Fig. 2. (a) JJA MLDAs averaged in NEPac (black box, Fig. 1a) for two observational groupings (red/orange) and ensemble means of CESM1-LE (black) and CMIP5 (blue). Shading for each time series represents the full range (min-to-max) across respective ensembles. (b) Probability distributions of JJA ensemble mean CESM1-LE MLDAs averaged in NEPac during the "present" (blue; 2005-34) and "future" (orange; 2070-99). Vertical black lines mark JJA 2019 MLDA values from GODAS (solid) and Argo (dashed) data averaged in same region. 
(a)

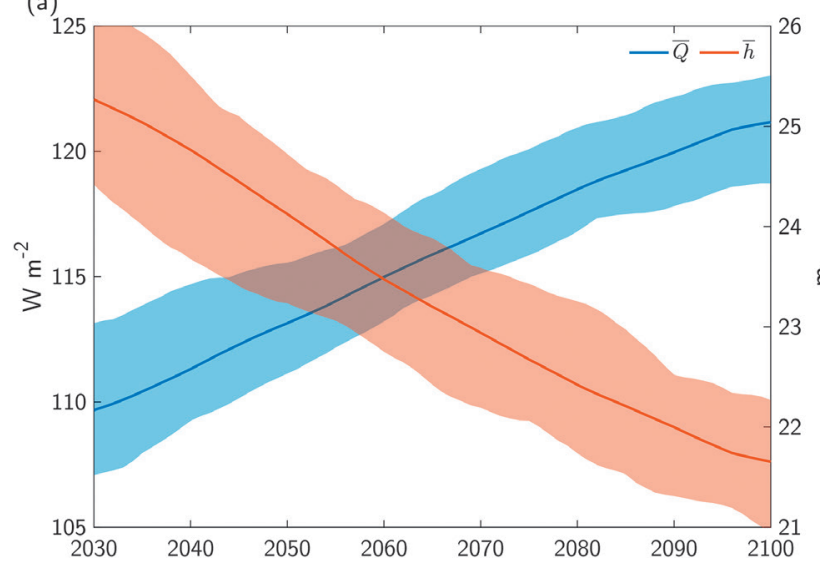

(b)

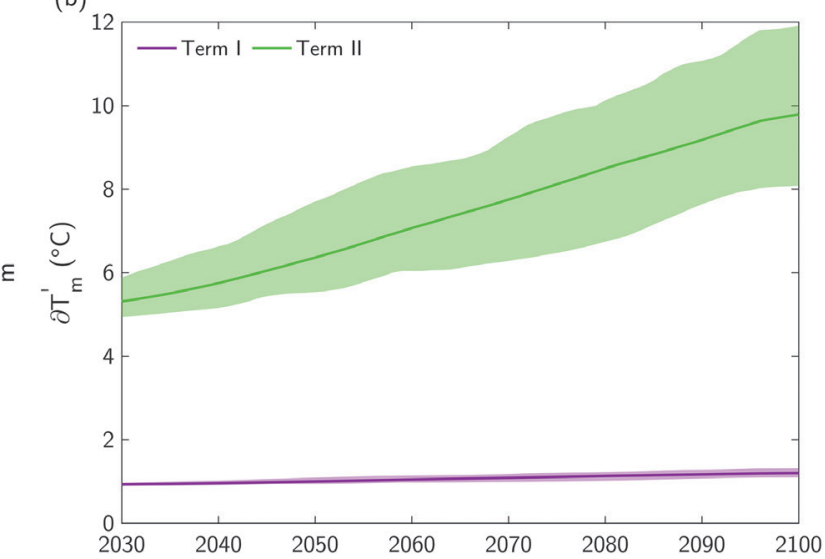

Fig. 3. (a) CESM1-LE JJA mean net surface heat flux ( $\bar{Q}$; left axis; blue) and mean MLD ( $\bar{h}$; right axis; red) in the NEPac (black box, Fig. 1). (b) Contributions of Eq. (1) terms I (purple) and II (green) to anomalous mixed layer temperature changes $\left(\partial T_{m}^{\prime}\right)$. Each term in (b) is calculated using the time-evolving means in (a) and a fixed net surface heat flux anomaly $\left(Q^{\prime}\right)$ and MLDA ( $\left.h^{\prime}\right)$ set to observed JJA 2019 values (see text). Terms I and II are calculated in 30-yr sliding windows starting in 2001; years along the $x$ axis denote the end of the window. For example, term I in 2060 represents fixed $Q^{\prime}$ divided by the projected CESM1-LE $\bar{h}$ for the period 2031-60. CESM1-LE data are subject to a 10-yr running mean prior to calculating changes.

entrainment and ocean-atmosphere feedbacks, extreme MLDAs like that in 2019 will contribute to larger and/or more frequent SST extremes in the future.

\section{Discussion.}

We have investigated the influence of climate change on North Pacific MLD trends and, by extension, the likelihood and intensity of the summer 2019 MHW. We showed that some parts of the NEPac have likely experienced long-term MLD shoaling since 1980 (i.e., within the black box in Fig. 1), but significant observational uncertainty regarding the strength of these trends remains (Fig. ES1 and Table 1). Even so, the 2019 MLDAs, which were an important driver of Blob 2.0 (A2020), were likely exacerbated by these multidecadal trends. Consequently, the marine ecosystem impacts generated by this MHW (PFMC 2020; Lambert 2019) may have also been intensified by the shoaling of the ocean mixed layer.

The anthropogenic contribution to these observed MLD trends is less clear. There is model uncertainty in the strength and pattern of the estimated forced NEPac trends from 1980-2015 (Figs. 1e,f, Tables 1 and ES1). Additionally, the fact that the observed MLD trend greatly exceeds the forced trends estimated by the model ensemble means (Table 1) suggests that internal variability makes a strong contribution to the observed trend. However, given the close spatial correspondence between Fig. 1c and the forced trends from 2016 to 2099, it is possible that the models underestimate the strength of the forced response in recent decades. Regardless, it is clear that large internal climate variability complicates the detectability of the forced MLD signal in observations.

Our analysis supports previous findings that pronounced changes in mean MLD may have significant implications for the frequency and strength of MHWs in the future (Alexander et al. 2018). This causal link arises primarily through an enhanced role for the MLDA effect on SSTA (Fig. 3b, term II), which will be further exacerbated as extreme negative MLDAs become more common in response to climate change (Fig. 2b). This process is likely to be more important in summer when mean MLDs are shallowest (Alexander and Penland 1996; Alexander et al. 2000). A shallower MLD and associated smaller heat capacity could further intensify SST warming in summer, contributing to thermal stress on marine organisms. More research is needed into mechanisms that may offset the projected effects of a shallower MLD on future MHWs. Finally, our results emphasize the importance of focusing on the underlying dynamics 
that modulate the mixed layer heat budget when assessing the influence of climate change on future MHWs, which complements recent studies focusing primarily on the influence of climate change on the SST itself (Frölicher et al. 2018; Jacox et al. 2018; Walsh et al. 2018).

Acknowledgments. Three referees, Stephanie Herring, and Robin Webb provided important comments. James Scott provided MLD estimates from the CMIP5 models. The views expressed herein are those of the authors and do not necessarily reflect the views of NOAA or the DOC. NCAR, sponsored by NSF, partly supported this work. Funding from NSF (OCE1600283, OCE1637632, and OCE2022868) and NOAA (MAPP NA17OAR4310106) is also appreciated.

\section{References}

Alexander, M. A., and C. Penland, 1996: Variability in a mixed layer ocean model driven by stochastic atmospheric forcing. J. Climate, 9, 2424-2442, https://doi.org/10.1175/1520-0442(1996)009<2424 :VIAMLO>2.0.CO;2.

— I. D. Scott, and C. Deser, 2000: Processes that influence sea surface temperature and ocean mixed layer depth variability in a coupled model. J. Geophys. Res., 105, 16823-16842, https://doi. org/10.1029/2000JC900074.

-, K. D. Friedland, K. E. Mills, J. A. Nye, A. J. Pershing, and A. C. Thomas, 2018: Projected sea surface temperatures over the 21st century: Changes in the mean, variability and extremes for large marine ecosystem regions of northern oceans. Elementa, 6, 9, https://doi.org/10.1525/elementa.191.

Amaya, D. J., N. E. Bond, A. J. Miller, and M. J. Deflorio, 2016: The evolution and known atmospheric forcing mechanisms behind the 2013-2015 North Pacific warm anomalies. US CLIVAR Variations Newsletter, No. 14, International CLIVAR Project Office, Southampton, United Kingdom, 1-6.

- A. J. Miller, S.-P. Xie, and Y. Kosaka, 2020: Physical drivers of the summer 2019 North Pacific marine heatwave. Nat. Commun., 11, 1903, https://doi.org/10.1038/s41467-020-15820-w.

Balmaseda, M. A., K. Mogensen, and A. T. Weaver, 2013: Evaluation of the ECMWF ocean reanalysis system ORAS4. Quart. J. Roy. Meteor. Soc., 139, 1132-1161, https://doi.org/10.1002/qj.2063.

Behringer, D., and Y. Xue, 2004: Evaluation of the global ocean data assimilation system at NCEP: The Pacific Ocean. Bull. Amer. Meteor. Soc., 5889-5894.

Bond, N. A., M. F. Cronin, H. Freeland, and N. Mantua, 2015: Causes and impacts of the 2014 warm anomaly in the NE Pacific. Geophys. Res. Lett., 42, 3414-3420, https://doi.org/10.1002/2015GL063306.

Capotondi, A., M. A. Alexander, N. A. Bond, E. N. Curchitser, and J. D. Scott, 2012: Enhanced upper ocean stratification with climate change in the CMIP3 models. J. Geophys. Res., 117, C04031, https:// doi.org/10.1029/2011JC007409.

Carton, J. A., G. A. Chepurin, and L. Chen, 2018: SODA3: A new ocean climate reanalysis. J. Climate, 31, 6967-6983, https://doi.org/10.1175/ JCLI-D-18-0149.1.

Cavole, L. M., and Coauthors, 2016: Biological impacts of the 2013-2015 warm-water anomaly in the northeast Pacific: Winners, losers, and the future. Oceanography, 29, 273-285, https://doi.org/10.5670/ oceanog.2016.32.
Frölicher, T. L., E. M. Fischer, and N. Gruber, 2018: Marine heatwaves under global warming. Nature, 560, 360-364, https://doi.org/10.1038/ s41586-018-0383-9.

Hosoda, S., T. Ohira, and T. Nakamura, 2008: A monthly mean dataset of global oceanic temperature and salinity derived from Argo float observations. JAMSTEC Rep. Res. Dev., 8, 47-59, https://doi. org/10.5918/jamstecr.8.47.

Jacox, M. G., M. A. Alexander, N. J. Mantua, J. D. Scott, G. Hervieux, R. S. Webb, and F. E. Werner, 2018: Forcing of multiyear extreme ocean temperatures that impacted California Current living marine resources in 2016. Bull. Amer. Meteor. Soc., 99, S27-S33, https://doi. org/10.1175/BAMS-D-17-0119.1.

Kay, J. E., and Coauthors, 2015: The Community Earth System Model (CESM) Large Ensemble Project: A community resource for studying climate change in the presence of internal climate variability. Bull. Amer. Meteor. Soc., 96, 1333-1349, https://doi.org/10.1175/ BAMS-D-13-00255.1.

Lambert, H. R., 2019: 2019 albacore catch blows old record out of the water. KOIN.com, accessed 10 May 2020, https://www.koin.com/news/ oregon/2019-albacore-catch-blows-old-record-out-of-the-water/.

NOAA, 2019: New marine heatwave emerges off West Coast, resembles "the Blob". NOAA, accessed 8 May 2020, https://www.fisheries. noaa.gov/feature-story/new-marine-heatwave-emerges-westcoast-resembles-blob.

PFMC, 2020: Review of 2019 Ocean Salmon Fisheries: Stock Assessment and Fishery Evaluation Document for the Pacific Coast Salmon Fishery Management Plan, Pacific Fishery Management Council, 7700 NE Ambassador Place, Suite 101, Portland, OR 97220-1384, 347 pp.

Piatt, J. F., and Coauthors, 2020: Extreme mortality and reproductive failure of common murres resulting from the northeast Pacific marine heatwave of 2014-2016. PLOS ONE, 15, e0226087, https://doi. org/10.1371/journal.pone.0226087.

Suga, T., K. Motoki, Y. Aoki, and A. M. MacDonald, 2004: The North Pacific climatology of winter mixed layer and mode waters.J. Phys. Oceanogr., 34, 3-22, https://doi.org/10.1175/1520-0485(2004)034<0003:TNPCOW $>2.0 . C 0 ; 2$.

Taylor, K. E., R. J. Stouffer, and G. A. Meehl, 2012: An overview of CMIP5 and the experiment design. Bull. Amer. Meteor. Soc., 93, 485-498, https://doi.org/10.1175/BAMS-D-11-00094.1. 
Walsh, J. E., and Coauthors, 2018: The high-latitude marine heat wave of 2016 and its impacts on Alaska. Bull. Amer. Meteor. Soc., 99, S39S43, https://doi.org/10.1175/BAMS-D-17-0105.1.
Zuo, H., M. A. Balmaseda, S. Tietsche, K. Mogensen, and M. Mayer, 2019: The ECMWF operational ensemble reanalysis-analysis system for ocean and sea ice: A description of the system and assessment. Ocean Sci., 15, 779-808, https://doi.org/10.5194/os-15-779-2019. 